\title{
EVALUATION OF A STRUCTURED TRAINING PROGRAM FOR TEACHING IMMUNIZATION SKILLS TO INTERNS
}

\author{
Priya Senthil Kumar1, Saravana Kumar Palaniappan²
}

${ }_{1}^{1}$ Associate Professor, Department of Community Medicine, Kilpauk Medical College, Chennai, Tamilnadu, India.

${ }^{2}$ Associate Professor, Department of Community Medicine, Stanley Medical College, Chennai, Tamilnadu, India.

ABSTRACT
BACKGROUND
Immunization is recognised as one of the strategies to reduce vaccine preventable diseases. Competency in immunization is very
important for medical students and currently there is no structured Immunization training programme in medical schools. Hence,
this study proposes to develop a structured training and evaluate its effectiveness.
Aim- To develop a structured training program for the interns on skills of Immunization and evaluate the effectiveness of the same.

\section{MATERIALS AND METHODS}

A quasi-experimental study was conducted among 30 interns in Departments of Community Medicine and Paediatrics in Kilpauk Medical College, Chennai during May - June 2018. A pre-test assessment of cognitive domain in Immunization was assessed. Twostep training- first a small group teaching for knowledge, second skill training by observation in Immunization clinic and administering under supervision. The effectiveness of the training was assessed after 4 weeks by a questionnaire and OSCE.

\section{RESULTS}

The mean pre-test score was 16.27 (SD 3.8) and post-test was 25.1 (SD 3.36). The difference of means was 8.8 (95\% CI of 6.8-10.2). The difference of means was 1.9 (CI 1.25-2.55) for knowledge on National Immunization Schedule and 1.2 (CI 0.88-1.52) for knowledge on AEFI. Mean OSCE score was 9.23 (total 10) for skill and 3.5 (total 4) for communication. The proportion of interns administering vaccines after the training also increased from $20 \%$ to $86.7 \%$ for BCG, $10 \%$ to $100 \%$ for Pentavalent, $26.7 \%$ to $83.3 \%$ for Hepatitis-B, $3.3 \%$ to $63.3 \%$ for MMR and $60 \%$ to $100 \%$ for OPV with significant difference (p $<0.0001)$.

\section{CONCLUSION}

The structured training has significantly improved the knowledge and immunization skills of interns.

\section{KEY WORDS}

Structured Training, Knowledge, Skills, Immunization, Interns.

HOW TO CITE THIS ARTICLE: Kumar PS, Palaniappan SK. Evaluation of a structured training program for teaching immunization skills to interns. J. Evolution Med. Dent. Sci. 2018;7(49):5229-5231, DOI: 10.14260/jemds/2018/1160

\section{BACKGROUND}

Immunization is one of the proven interventions in primary prevention of Vaccine Preventable Diseases of the Infancy and Childhood. ${ }^{1}$ The nationwide coverage of Immunization of children aged 12 - 23 months has improved from $43.5 \%$ (NFHS 3$)^{2}$ to $62 \%$ (NFHS 4 ), ${ }^{3}$ but still the overall coverage is low. Low level of coverage of Immunization is attributed to low morale and lack of information on the safety of vaccines among the vaccine-hesitant parents. ${ }^{4}$ Knowledge and Procedural skills are of prime importance among the Health care providers, particularly the medical professionals to administer the vaccines along with counselling.5 Parental interaction with the health personnel is a critical determinant that shapes the attitude of parents on vaccination of their children. ${ }^{6}$ There is no structured program on training skills on Immunization among the interns in the Medical College.

'Financial or Other Competing Interest': None.

Submission 24-10-2018, Peer Review 17-11-2018,

Acceptance 23-11-2018, Published 03-12-2018.

Corresponding Author:

Saravana Kumar Palaniappan,

Associate Professor,

Department of Community Medicine,

Stanley Medical College,

Chennai-600001,

Tamilnadu, India

E-mail: drsaran77@gmail.com

DOI: $10.14260 /$ jemds $/ 2018 / 1160$

\section{(c) $($ ) $\$$}

It is therefore essential to train the interns on knowledge, skills of administration of vaccines and communication for gaining competence in implementing the program on Immunization in the community in future. This study aims to implement a structured training program on knowledge and procedural skills among the interns and evaluate the effectiveness for the same.

\section{MATERIALS AND METHODS}

A quasi-experimental study was conducted among the 30 interns in the Department of Community Medicine and Paediatrics in Govt. Kilpauk Medical College in Chennai, Tamilnadu, India, during May to June 2018. A pre-test assessment of cognitive domain on the knowledge in Immunization was assessed before the implementation of training program. A two-step training program wherein first a small group teaching on the aspects of knowledge on Immunization was conducted followed by second step of training in skills by observation in Immunization clinic and administering the vaccines under supervision. The effectiveness of the training was assessed after 4 weeks by a questionnaire and OSCE. The data was analysed using SPSS version 16. Likert scale was used to assess the cognitive domain. Paired T-test was used for test of significance.

\section{RESULTS}

This study was conducted among 30 interns who posted in the Department of Paediatrics and Community Medicine, of whom 17 were males and the rest were female interns. The 
pre-test cognitive assessment of the knowledge of Immunization among the interns revealed an overall Mean score of 16.27 (S.D.3.8), particularly on knowledge on National Immunization schedule the Mean score was 8.57 (S.D.1.57) and that on Adverse Events following Immunization (AEFI) was score 1.5 (S.D.0.73). Following a two-step training program with small group teaching program on knowledge on Immunization, post-test score was as follows: Mean score of 25.1 (S.D.3.36), particularly on knowledge on National Immunization schedule. The Mean score was 10.47 (S.D. 0.9) and that on Adverse Events following Immunization (AEFI) was score 2.7 (S.D.0.65). The difference in Means for the overall cognitive domain pre- and post-test intervention is given in Table 1, which was statistically significant. Following the second step of training program in the form of observation in the Immunization session and administration of vaccines by the interns under supervision of the teaching faculty, the OSCE score of psychomotor domain was observed to be of Mean 9.23 (S.D.0898) and Communication skill was observed to be of Mean 3.5 (S.D. 0.682) Table 2.

Overall confidence of the interns to administer the vaccines under supervision improved as evidenced by the improvement in the proportion of interns who administered the vaccines after the training program than what they used to do previous to the training as given in Fig 1. A significant difference in the confidence level of the interns to administer all the vaccines as per the National Immunization schedule, particularly BCG given intradermally and Measles vaccine given subcutaneously to the children.

\begin{tabular}{|c|c|c|c|}
\hline & $\begin{array}{c}\text { Pre-test } \\
\text { Mean (SD) }\end{array}$ & $\begin{array}{c}\text { Post-test } \\
\text { Mean (SD) }\end{array}$ & $\begin{array}{c}\text { Difference of } \\
\text { Means (95\% CI) }\end{array}$ \\
\hline $\begin{array}{c}\text { Total Score } \\
\text { out of 32) }\end{array}$ & $16.27(3.8)$ & $25.1(3.36)$ & $8.8(6.8-10.82)$ \\
\hline $\begin{array}{c}\text { Knowledge on } \\
\text { NIS (11) }\end{array}$ & $8.57(1.57)$ & $10.47(0.9)$ & $1.9(1.25-2.55)$ \\
\hline $\begin{array}{c}\text { Knowledge on } \\
\text { AEFI (3) }\end{array}$ & $1.5(0.73)$ & $2.7(0.65)$ & $1.2(0.88-1.52)$ \\
\hline Table 1. Comparison of Pre-test and Post-test Scores on \\
Cognitive Domain of Immunization
\end{tabular}

\begin{tabular}{|c|c|c|}
\hline & Skills (Out of 10) & Communication (4) \\
\hline Mean & 9.23 & 3.5 \\
\hline SD & 0.898 & 0.682 \\
\hline Maximum & 10 & 4 \\
\hline Minimum & 7 & 2 \\
\hline Table 2. Skills on Administration and Communication \\
regarding Immunization \\
\hline
\end{tabular}

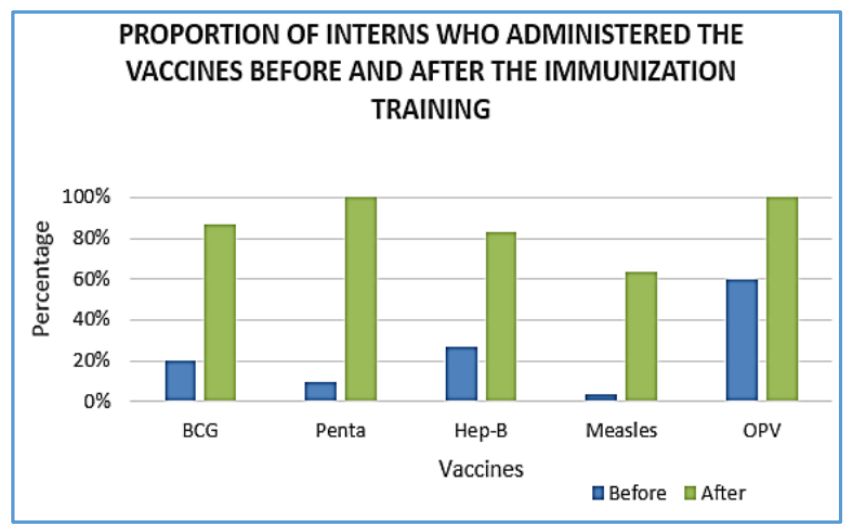

Figure 1. Proportion of Interns administering Vaccines

\section{DISCUSSION}

Vaccination represents an essential component of Preventive Medicine. In this study the knowledge on Immunization, adverse events following Immunization among the Interns improved after a structured training program addressing the cognitive domain, so as to motivate them to have confidence in handling vaccines. Similar studies conducted on Medical students in Germany by Betsch $\mathrm{C}$ et al revealed the importance of assessing the knowledge of students regarding vaccines for the creation of targeted educational interventions to enable students for patient interactions related to immunization. ${ }^{7}$ Afonso $\mathrm{N}$ et al also reported the potential value of the educational interventions, which are targeted towards medical students with regard to imparting skills on Immunization. ${ }^{8}$

In this study the skills of administration, confidence among the interns and communication skills showed good improvement after the training program and administration of vaccines under medical supervision. Martin IG et al reported that Objective Structured Clinical Examination (OSCE) played a key role in imparting the psychomotor skills among the medical students to administer vaccines as well as communicate to the parents regarding the adverse events following Immunization. ${ }^{9}$ The introduction of specific teaching and learning modalities and core competencies regarding Immunization may effectively address the issue of boosting the confidence among the medical students to improve their quality of own personal awareness and ability to educate the patients also. ${ }^{9}$ In our study also, OSCE supported by the cognitive skills of the interns improved the skills of administration of vaccines under medical supervision as well as communication with the caregivers regarding the adverse events following Immunization and the next scheduled visit for vaccination. Fraser $\mathrm{K}$ et al also concluded in their study that the role of simulation in imparting psychomotor skills in Immunization is major in medical education, wherein the confidence of the students get boosted up in simulators enabling them to administer in real life in future. ${ }^{10}$

Leask J et al ${ }^{11}$ and Smiljana $\mathrm{J}^{12}$ et al emphasised the need for improvement in knowledge, attitude and practices of Immunization among the medical students for effective implementation of program on Immunization at national level. Thus, there is a strong need for structured program in Medical Colleges for students addressing the cognitive domain and skills of administration of vaccines along with communication skills towards the parents of the beneficiaries for successful implementation of the national program on Immunization.

\section{CONCLUSION}

The structured training has significantly improved the knowledge and immunization skills of interns reflecting the strong need to implement it for gaining competency in Immunization.

\section{ACKNOWLEDGEMENT}

We thank all the faculty in the Departments of Community Medicine and Paediatrics who have supervised the skills of administration of vaccines by the interns on children attending the Immunization clinic. We also extend our gratitude to the parents and the children who have taken part in the training program. 


\section{REFERENCES}

[1] Gunardi H, Sekartini R, Werdhani RA, et al. Immunization Competence retention in Medical Students: a comparison between conventional lectures and lectures with simulation method. Paediatr Indones 2015;55(6):339-44.

[2] National Family Health Survey - 3. Mumbai. International Institute for Population Sciences. 200708. http:// www.nfhsindia.org/data/india/indch.pdf7

[3] National Family Health Survey - 4. Mumbai. International Institute for Population Sciences. 201415. http:// www.nfhsindia.org/data/india/indch.pdf7

[4] Healy CM, Pickering LK. How to communicate with Vaccine-hesitant parents. Pediatrics 2011;127(Suppl 1):S127-33.

[5] Larson HJ, Cooper LZ, Eskola J, et al. Addressing the vaccine confidence gap. Lancet 2011;378(9790):52635.

[6] Hausberg MC, Hergert A, Kroger C, et al. Enhancing Medical students' communication skills: development and evaluation of an undergraduate training program. BMC Med Educ 2012;12:16.
[7] Betsch C, Wicker S. E-health use, vaccination knowledge and perception of own risk: drivers of vaccination uptake in medical students. Vaccine 2012;30(6):1143-8.

[8] Afonso N, Kavanaugh M, Swanberg S. Improvement in attitudes toward Influenza vaccination in medical students following an integrated curricular intervention. Vaccine 2014;32(4):502-6.

[9] Martin IG, Jolly B. Predictive validity and estimated cut score of an objective structured clinical examination (OSCE) used as an assessment of clinical skills at the end of the first clinical year. Medical Education 2002;36(5):418-25.

[10] Fraser K, Ma I, Teteris E, et al. Emotion, cognitive load and learning outcomes during simulation training. Medical Education 2012;46(11):1055-62.

[11] Leask J, Quinn HE, Macartney K, et al. Immunization attitude, knowledge and practices of health professionals in regional NSW. Aust N Z J Public Health 2008;32(3):224-9.

[12] Cvjetkovic SJ, Jeremic VL, Tiosavljevic DV. Knowledge and attitudes toward vaccination: a survey of Serbian students. J Infection \& Pub Health 2017;10(5):649-56. 